\title{
The Central Kink Region of Fowlicidin-2, an $\alpha$-Helical Host Defense Peptide, Is Critically Involved in Bacterial Killing and Endotoxin Neutralization
}

\author{
Yanjing Xiao $^{a}$ Alvaro I. Herrera ${ }^{c}$ Yugendar R. Bommineni $^{a} \quad$ Jose L. Soulages ${ }^{b}$ \\ Om Prakash ${ }^{c}$ Guolong Zhang ${ }^{a}$
}

Departments of a Animal Science and ${ }^{\mathrm{b}}$ Biochemistry and Molecular Biology, Oklahoma State University, Stillwater, Okla., and ${ }^{C}$ Department of Biochemistry, Kansas State University, Manhattan, Kans., USA

\begin{abstract}
Key Words
Host defense peptide $\cdot$ Antimicrobial peptides • Cathelicidins $\cdot$ Innate immunity $\cdot$ Structure-activity relationship · Endotoxin · Antibiotic resistance
\end{abstract}

\begin{abstract}
Fowlicidins are a group of newly identified chicken cathelicidin host defense peptides. We have shown that the putatively mature fowlicidin-2 of 31 amino acid residues possesses potent antibacterial and lipopolysaccharide (LPS)neutralizing activities, but with a noticeable toxicity to mammalian cells. As a first step in exploring the structureactivity relationships of fowlicidin-2, in this study we determined its tertiary structure by nuclear magnetic resonance spectroscopy. Unlike the majority of cathelicidins, which are composed of a predominant $\alpha$-helix with a short hinge sequence near the center, fowlicidin- 2 consists of 2 well-defined $\alpha$-helical segments (residues 6-12 and 23-27) connected by a long extensive kink (residues 13-20) induced by proline. To further investigate the functional significance of each of these structural components, several $\mathrm{N}$ - and C-terminal deletion analogs of fowlicidin-2 were synthesized and analyzed for their antibacterial, cytotoxic and LPS-neutralizing activities. Our results indicated that neither the $\mathrm{N}$ - nor C-terminal $\alpha$-helix alone is sufficient to confer any function. Rather, fowlicidin-2(1-18) and fowlicidin-2(15-31), $2 \alpha$-helical segments with inclusion of the central cationic kink region, retained substantial capacities to kill bacteria and neutralize
\end{abstract}

the LPS-induced proinflammatory response, relative to the parent peptide. More desirably, these 2 peptide analogs showed substantially reduced toxicity to human erythrocytes and epithelial cells, indicative of improved potential as antibacterial and antisepsis agents. To our knowledge, fowlicidin-2 is the first $\alpha$-helical cathelicidin, with the central kink region shown to be critically important in killing bacteria and neutralizing LPS.

Copyright $\odot 2008$ S. Karger AG, Basel

\section{Introduction}

With the rapid emergence of antibiotic-resistant pathogens, there is an unprecedented urgency to develop new antimicrobials to which these organisms are less prone to gain resistance. Cationic host defense peptides are an integral component of innate immunity and are found in virtually all living species. They are capable of killing a variety of pathogens and have a similar efficiency against strains resistant and susceptible to antibiotics [1-3]. Most cationic peptides have nonspecific membrane-lytic activities, which are much more difficult for bacteria to develop resistance to than to conventional antibiotics $[1,4,5]$. Therefore, these peptides are being actively explored as a new class of antimicrobials.

Y.X. and A.H. contributed equally to this paper.

\section{KARGER}

(๑) 2008 S. Karger AG, Basel

Fax +4161306 1234

E-Mail karger@karger.ch

www.karger.com
Accessible online at: www.karger.com/jin
Dr. Guolong Zhang

Department of Animal Science, Oklahoma State University

212D Animal Science Bldg

Stillwater, OK 74078 (USA)

Tel. +1 405744 6619, Fax +1 405744 7390, E-Mail zguolon@okstate.edu 
Table 1. Fowlicidin-2 and its analogs

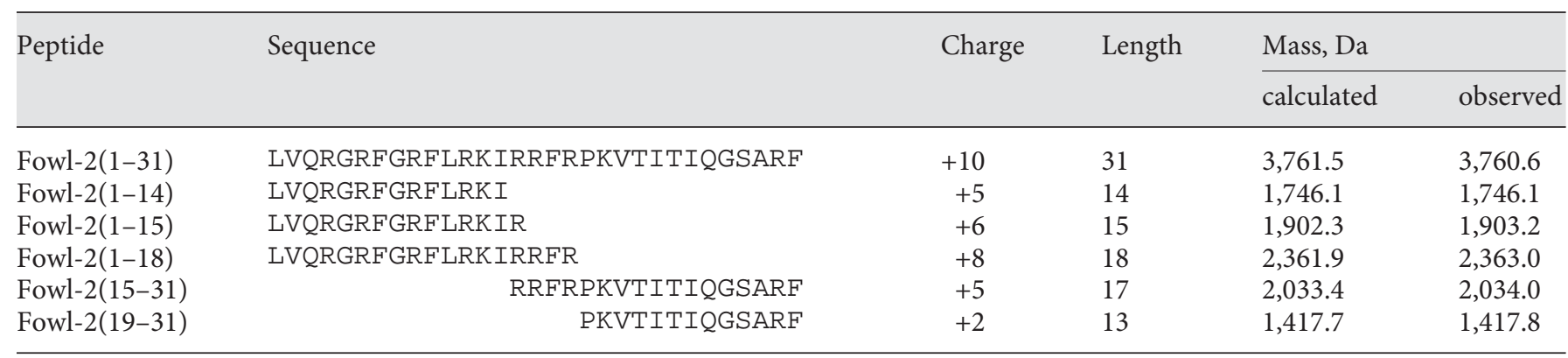

However, several major barriers impede the development of cationic peptides as therapeutic agents. Factors such as salt and serum suppress the microbicidal activities of a majority of these peptides [6-8]. There is also noticeable toxicity to host cells associated with many of these peptides. Various strategies are being pursued in attempts to reduce the toxicity and enhance the antimicrobial efficacy and serum stability of these peptides. To date, a number of structure-activity relationship studies have led to the identification of novel peptide analogs with better therapeutic potentials. They have done this by altering certain physicochemical and structural properties, such as charge, amphipathicity, hydrophobicity, degree of structuring ( $\alpha$-helix or $\beta$-sheet), D-isomerization and cyclization [9-12].

Cathelicidins, a major family of vertebrate antimicrobial host defense peptides, are receiving particular attention as novel antimicrobials, due to their simple structures and high antibacterial efficacy relative to other families of cationic peptides [13-16]. In addition to a broad spectrum of antimicrobial activities, many cathelicidins have the capacity to directly bind lipopolysaccharide (LPS) and lipoteichoic acid in vitro and suppress Gram-negative and Gram-positive bacteria-induced septic shock in vivo [1719]. Thus, these cathelicidins may also represent excellent therapeutic candidates for sepsis treatment.

We previously reported the identification of 3 novel chicken cathelicidins, namely fowlicidins $1-3$, with highly potent antibacterial and LPS-neutralizing activities $[20,21]$. In comparison with fowlicidin-1, fowlicidin-2 exhibited similar antibacterial efficacy with less lytic activity to host cells [20]. To further reduce the toxicity of fowlicidin-2, in this report we first determined the tertiary structure of fowlicidin-2 by nuclear magnetic resonance (NMR) spectroscopy. Based on the structural information, several deletion analogs were further designed and analyzed for their antibacterial, cytotoxic, membrane- permeabilizing and LPS-neutralizing activities. We demonstrated that 4 amino acids in the central kink region (residues 15-18) are critically important in peptide-membrane interactions as well as in bacterial killing and LPS neutralization. We further identified that 2 short peptide analogs that contained either the $\mathrm{N}$ - or $\mathrm{C}$-terminal helical segment together with residues 15-18 retain substantial antibacterial and LPS-neutralizing activities but have a significantly reduced cytotoxicity, relative to the parent peptide.

\section{Materials and Methods}

\section{Peptide Synthesis}

Fowlicidin-2 was synthesized using the standard solid-phase method by SynPep (Dublin, Calif., USA) and its analogs by BioSynthesis (Lewisville, Tex., USA; table 1). The peptides were purified through reverse-phase HPLC and obtained at $>95 \%$ purity. The mass and purity of each peptide were further confirmed by MALDI-TOF mass spectrometry using the Voyager DePro instrument (Applied Biosystems, Foster City, Calif., USA) housed in the recombinant DNA/protein resource facility of Oklahoma State University. The average mass of each peptide determined by mass spectrometry was consistent with the mass calculated from the sequence (table 1).

\section{Circular Dichroism Spectroscopy}

To determine the secondary structure of fowlicidin-2 and its analogs, circular dichroism (CD) spectroscopy was performed with a Jasco-715 spectropolarimeter using a $0.1-\mathrm{cm}$ path length cell over the 180 - to 260 -nm range, as we previously described [21, 22]. The spectra were acquired at $25^{\circ} \mathrm{C}$ every $1 \mathrm{~nm}$, with a 2 -second averaging time per point and a 1-nm band pass. Peptides (10 $\mu \mathrm{M}$ ) were measured in $50 \mathrm{~mm}$ potassium phosphate buffer, $\mathrm{pH} 7.4$, with or without different concentrations of trifluoroethanol (TFE) $(0,10,20,40$ and $60 \%)$ or sodium dodecyl sulfate (SDS) micelles (0.25 and 0.5\%). Mean residue ellipticity (MRE) was expressed as $[\theta]_{\text {MRE }}\left(\mathrm{deg} \cdot \mathrm{cm}^{2} \cdot \mathrm{dmol}^{-1}\right)$. The contents of 6 types of secondary structural element (regular and distorted $\alpha$-helix, regular and distorted $\beta$-sheet, turns and unordered structures) were analyzed with the program Selcon3 [23]. 


\section{Nuclear Magnetic Resonance Spectroscopy}

To determine the solution structure of fowlicidin-2, 2-dimensional ${ }^{1} \mathrm{H}-{ }^{1} \mathrm{H}$ nuclear magnetic resonance (NMR) experiments were performed with an 11.75-tesla UnityPlus spectrometer (Varian, Palo Alto, Calif., USA), operating at $499.96 \mathrm{MHz}$, with a 3-mm triple-resonance inverse detection probe. Fowlicidin-2 (3 mM) was used to record total correlation spectroscopy (TOCSY) and nuclear overhauser enhancement spectroscopy (NOESY) NMR experiments at $25^{\circ} \mathrm{C}$ in $50 \%$ deuterated TFE $\left(\mathrm{TFE}-\mathrm{d}_{3}\right) / 50 \%$ $\mathrm{H}_{2} \mathrm{O}$, essentially as described $[21,22]$. A series of 1-dimensional experiments were conducted from 5 to $35^{\circ} \mathrm{C}$, at $5^{\circ} \mathrm{C}$ increments. Water peak suppression was obtained by low-power irradiation of the $\mathrm{H}_{2} \mathrm{O}$ resonance. A total of 256 increments of $4 \mathrm{~K}$ data points were recorded for the 2-dimensional experiments. All data sets were obtained in the hypercomplex phase-sensitive mode. TOCSY spectra were recorded by using MLEV-17 for isotropic mixing for $100 \mathrm{~ms}$ at a B1 field strength of $8 \mathrm{KHz}$. NOESY experiments were performed with mixing times of 100,300 and $400 \mathrm{~ms}$, and the residual TFE methylene peak $(3.88 \mathrm{ppm})$ was used as a reference for the chemical-shift values. Varian software, VNMR 6.1C, on a Silicon Graphics Octane workstation was used for data processing, and Sparky 3 software (Goddard and Kneller, University of California, San Francisco, Calif., USA) was used for data analysis.

\section{Structure Calculation}

Proton resonance assignments were made using 2-dimensional TOCSY for intra-residue spin systems and NOESY spectra for inter-residue connectivities, as previously described [24]. A total of 174 distance constraints obtained from the NOESY spectrum were used for structure calculations. A mixing time of $300 \mathrm{~ms}$ was initially used for distance constraint measurements and the assigned peaks were then checked with the NOESY spectra obtained with a $100-\mathrm{ms}$ mixing time. NOE peaks were classified as intra-residue, sequential, medium and long range. NOE cross peak intensities were classified as strong (1.8-2.7 $\AA$ ), medium (1.8-3.5 $\AA$ ), weak (1.8-4.0 $)$ and very weak (1.8-5.0 $)$ ). Upper distance limits for NOEs involving methyl protons and non-stereospecifically assigned methylene protons were corrected appropriately by adding 1 A to the constraints for center averaging [25]. The obtained distance restraints were then used to create initial peptide structures starting from extended structures using the Crystallography and NMR System (CNS), version 1.1 [26], which uses both a simulated annealing protocol and molecular dynamics to produce low-energy structures with minimum distance and geometry violations. Default parameters were used to generate 100 structures for the initial CNS run. A second round of calculations generated 20 structures, from which the 10 with the lowest energy and no restriction violations and were selected and analyzed with Sybyl 7.1 (Tripos, St. Louis, Mo., USA). The surface accessibilities of fowlicidin-2 were generated using GRASP [27].

\section{Antibacterial Assay}

Three representative Gram-negative bacteria (Escherichia coli ATCC 25922, Salmonella enterica Serovar Enteritidis ATCC 13076 and Klebsiella pneumoniae ATCC 13883) and 4 Gram-positive bacteria (Listeria monocytogenes ATCC 19115, Staphylococcus aureus ATCC 25923, and 2 methicillin-resistant strains, $S$. aureus ATCC BAA-39 and S. aureus ATCC 43300) were purchased from ATCC (Manassas, Va., USA) or MicroBiologics (St.
Cloud, Minn., USA). The antibacterial activities of fowlicidin-2 and its analogs were tested by using a modified broth microdilution assay in the bicarbonate buffer to better mimic physiological environments, as previously described [28]. Briefly, bacteria were cultured overnight in tryptic soy broth (TSB) at $37^{\circ} \mathrm{C}$, diluted $1: 1,000$ in fresh subculture medium containing $20 \%$ TSB, $10 \%$ fetal bovine serum (FBS), $100 \mathrm{~mm} \mathrm{NaCl}, 25 \mathrm{mM} \mathrm{NaHCO}_{3}$ and $1 \mathrm{mM} \mathrm{NaH}_{2} \mathrm{PO}_{4}$, and grown to the mid-log phase. Cells were then washed twice with $10 \mathrm{~mm}$ sodium phosphate buffer, $\mathrm{pH} 7.4$, and resuspended to $5 \times 10^{5}$ colony-forming units $(\mathrm{CFU}) / \mathrm{ml}$ in the assay medium containing 20\% TSB, $25 \mathrm{mM} \mathrm{NaHCO}_{3}$ and $1 \mathrm{~mm}$ $\mathrm{NaH}_{2} \mathrm{PO}_{4}$ [28]. If necessary, $100 \mathrm{mM} \mathrm{NaCl}$ was incorporated to test the effect of salinity on antibacterial activity. Bacteria $(90 \mu \mathrm{l})$ were dispensed into 96 -well plates, followed by addition in duplicate of $10 \mu \mathrm{l}$ of peptides in serial 2 -fold dilutions in $0.01 \%$ acetic acid. The minimum inhibitory concentration (MIC) of each peptide against each bacterial strain was determined as the lowest concentration that gave no visible bacterial growth after overnight incubation at $37^{\circ} \mathrm{C}$.

\section{Effect of Serum on the Antibacterial Activity}

The influence of serum on the antibacterial activity of fowlicidin- 2 and its analogs was evaluated by the radial diffusion assay as described $[29,30]$. Briefly, S. aureus ATCC 25923 was grown in TSB to the mid-log phase, and washed twice with $10 \mathrm{~mm}$ sodium phosphate buffer, $\mathrm{pH} 7.4$, and then mixed evenly to $4 \times 10^{5} \mathrm{CFU} /$ $\mathrm{ml}$ with the underlay gel containing $10 \mathrm{mM}$ sodium phosphate buffer, $0.3 \mathrm{mg} / \mathrm{ml}$ of TSB powder and $1 \%$ (w/v) agarose. Sample wells ( $3 \mathrm{~mm}$ in diameter) were punched in the underlay gel. Peptides $(0.5$ or $1 \mu \mathrm{g})$, diluted in $4 \mu \mathrm{l}$ of $0.01 \%$ acetic acid containing 0,20 and $50 \%$ human serum, were added to each well. After $3 \mathrm{~h}$ of incubation at $37^{\circ} \mathrm{C}$, the overlay gel containing $6 \%$ TSB powder, $1 \%$ agarose and $10 \mathrm{~mm}$ sodium phosphate buffer ( $\mathrm{pH} 7.4$ ) was poured onto the underlay gel and incubated overnight at $37^{\circ} \mathrm{C}$ to visualize the bacterial clearance zones.

\section{Inner Membrane Permeabilization Assay}

The kinetics of permeabilizing bacterial cytoplasmic membranes by fowlicidin-2 and its analogs were determined using E. coli ML-35p, which constitutively expresses $\beta$-galactosidase in the cytosol but lacks lactose permease (kindly provided by Richard Gallo, University of California, San Diego, Calif., USA), as previously described $[21,28]$. The disruption of the E. coli ML$35 \mathrm{p}$ inner membrane results in the release of $\beta$-galactosidase, which in turn hydrolyzes $o$-nitrophenyl- $\beta$-D-galactopyranoside (ONPG), a chromogenic substrate to generate a color product, $o$-nitrophenol. Briefly, E. coli ML-35p was cultured overnight in TSB at $37^{\circ} \mathrm{C}$, diluted $1: 1,000$ and grown for an additional $3 \mathrm{~h}$ at $37^{\circ} \mathrm{C}$. Cells were washed twice with $10 \mathrm{~mm}$ sodium phosphate buffer, $\mathrm{pH} 7.4$, and diluted to $\mathrm{A}_{600}=0.03$ (equivalent to 2.5-5 $\times$ $10^{7} \mathrm{CFU} / \mathrm{ml}$ ) in the same buffer containing $1 \%$ TSB with and without $100 \mathrm{~mm} \mathrm{NaCl}$. Bacteria $(80 \mu \mathrm{l})$ were then dispensed into a 96-well plate, followed by addition of $0.5 \mathrm{MIC}$ of each peptide and $1.5 \mathrm{mM}$ of ONPG (Sigma, St. Louis, Mo., USA) to a total volume of $100 \mu \mathrm{l}$. Because the MIC of fowlicidin-2(19-31) could not be determined even at the highest peptide concentration tested $(>32$ $\mu \mathrm{M}), 16 \mu \mathrm{M}$ was used. The plate was incubated at $37^{\circ} \mathrm{C}$ for $1 \mathrm{~h}$ with shaking and it was read every 2 min to monitor the production of $o$-nitrophenol at $420 \mathrm{~nm}$. Negative controls contained no peptide but an equal volume of $0.01 \%$ acetic acid. 
Hemolytic Assay

The hemolytic activities of fowlicidin-2 and its analogs were determined as previously described [20-22]. Briefly, fresh anticoagulated human blood was collected, washed twice with PBS and diluted to $0.8 \%$ in PBS with or without $10 \%$ FBS. Erythrocytes $(90 \mu \mathrm{l})$ were dispensed into 96 -well plates, followed by addition in duplicate of $10 \mu \mathrm{l}$ of serially diluted peptides in $0.01 \%$ acetic acid. After incubation at $37^{\circ} \mathrm{C}$ for $2 \mathrm{~h}$, the plates were centrifuged at $800 \mathrm{~g}$ for $10 \mathrm{~min}$. The supernatants were transferred to new $96-$ well plates and the absorbance was measured at $405 \mathrm{~nm}$ for released hemoglobin. Negative controls contained cells suspended in PBS only and positive controls included cells suspended in $1 \%$ Triton X-100. Percent hemolysis was calculated as [ $\left(\mathrm{A}_{405} \mathrm{~nm}\right.$, peptide $\left.\left.\mathrm{A}_{405 \mathrm{~nm}, \mathrm{PBS}}\right) /\left(\mathrm{A}_{405 \mathrm{~nm}, 1 \% \text { Triton X-100 }}-\mathrm{A}_{405 \mathrm{~nm}, \mathrm{PBS}}\right)\right] \times 100$.

\section{Cytotoxicity Assay}

The toxicity was evaluated with human colonic epithelial Caco-2 cells (ATCC) using alamarBlue dye (Biosource, Carlsbad, Calif., USA), as previously described [20-22]. Briefly, cells were seeded into a 96-well plate at $5 \times 10^{4}$ cells/well in Dulbecco's modified Eagle's medium (DMEM) containing 20\% FBS. After overnight growth to $80-90 \%$ confluence at $37^{\circ} \mathrm{C}$ and in $5 \% \mathrm{CO}_{2}$, cells were washed once with DMEM, followed by addition of $90 \mu \mathrm{l}$ of fresh DMEM with and without $10 \%$ FBS and $10 \mu$ l of each peptide in duplicate (to a final concentration of 100 or $200 \mathrm{mM}$ ) into each well. After incubation for $18 \mathrm{~h}, 10 \mu \mathrm{l}$ of alamarBlue dye were added to each well and incubated for another $6 \mathrm{~h}$. The fluorescence was measured with excitation at $545 \mathrm{~nm}$ and emission at $590 \mathrm{~nm}$. Percent cell death was calculated as $\left[1-\left(\mathrm{F}_{\text {peptide }}-\mathrm{F}_{\text {background }}\right) /\right.$ $\left.\left(\mathrm{F}_{\text {acetic acid }}-\mathrm{F}_{\text {background }}\right)\right] \times 100$, where $\mathrm{F}_{\text {peptide }}$ is the fluorescence of cells exposed to peptides, $F_{\text {acetic acid }}$ is the fluorescence of cells exposed to $0.01 \%$ acetic acid only and $\mathrm{F}_{\text {background }}$ is the background fluorescence of $10 \%$ alamarBlue dye in DMEM without cells.

\section{Modulation of LPS-Induced Proinflammatory Response}

The effect of fowlicidin-2 and its analogs on the production of LPS-induced proinflammatory mediators was evaluated using mouse macrophage RAW264.7 cells (ATCC). Cells were seeded in 24 -well plates at $3 \times 10^{5}$ cells/well in DMEM containing $10 \%$ FBS and allowed to grow overnight to $80-90 \%$ confluence. After being washed twice with DMEM and replenished with fresh DMEM with or without $10 \%$ FBS, cells were treated with $0.1 \mu \mathrm{g} / \mathrm{ml}$ of LPS from E. coli O114:B4 (Sigma) together with $20 \mu \mathrm{M}$ of peptides in duplicate. The supernatants were removed, following incubation at $37^{\circ} \mathrm{C}$ for $24 \mathrm{~h}$, for analysis of tumor necrosis factor (TNF)- $\alpha$ concentrations by ELISA (R\&D Systems, Minneapolis, Minn., USA) and nitric oxide (NO) levels with Griess reagent (Molecular Probes, Eugene, Oreg., USA).

\section{Results}

\section{Solution Structure of Fowlicidin-2}

The secondary structure of fowlicidin-2 was determined by CD spectroscopy in different concentrations of TFE and SDS, as previously described [21, 22]. As shown in figure 1a, fowlicidin-2 was largely unstructured in phosphate buffer, but showed a dose-dependent enhance- ment in the $\alpha$-helical content in the presence of increasing concentrations of TFE. The $\alpha$-helicity rose from 3 to $36 \%$ as the TFE concentration increased from 10 to $60 \%$. An $\alpha$-helical content of $17 \%$ was also observed in 0.25 or $0.5 \%$ SDS micelles (fig. 1b).

Because fowlicidin-2 adopted a peak level of $\alpha$-helicity in 40-60\% TFE, 2-dimensional ${ }^{1} \mathrm{H}-{ }^{1} \mathrm{H}$ NMR spectroscopy was next performed to determine its tertiary structure in TFE: $\mathrm{H}_{2} \mathrm{O}(1: 1, \mathrm{v} / \mathrm{v})$, as previously described $[21,22]$. Sequence-specific resonance assignments were obtained using the TOCSY and NOESY spectra. The TOCSY spectra acquired at $25^{\circ} \mathrm{C}$ gave good chemical-shift dispersion with limited spectral overlap, enabling the assignment of the spin systems for all residues (online suppl. fig. S1, www.karger.com/doi/10.1159/000174822). A spatial distance constraint was assigned from each NOE specific peak in the NOESY spectra. The sequential and medium distance NOE connectivities as well as $\mathrm{C}_{\alpha}$-proton chemical-shift index $\left(\Delta \mathrm{C}_{\alpha \mathrm{H}}\right)$ are illustrated in figure 2. A number of nonsequential $\mathrm{d}_{\alpha \mathrm{N}(\mathrm{i}, \mathrm{i}+3)}$ NOEs that are indicative of regions of $\alpha$-helical conformation were observed from Gly $^{5}$ to $\mathrm{Phe}^{10}$ and from $\mathrm{Val}^{21}$ to $\mathrm{Arg}^{30}$. The characteristic chemical-shift index of these amino acids also confirmed the helical conformation in these 2 regions.

For structural calculations, a total of 174 NOE distance constraints involving 74 intraresidue, 53 sequential and 37 medium-range constraints were used (table 2). From 100 conformers calculated, 10 structures with the lowest energy were retained for further analysis. A Ramachandran plot, produced by Procheck-NMR [31], showed that $64.5 \%$ of residues are in the most favored region and $32.2 \%$ are in additional allowed regions (table 2). A superimposition of the 10 lowest energy structures showed a considerable degree of flexibility with a pairwise root mean square deviation of the backbone of $3.86 \AA$ (table 2). However, alignments along residues 6-12 and 23-27 of the 10 lowest energy structures showed backbone root mean square deviation values of 1.55 and $0.28 \AA$, respectively (table 2 ), suggesting the $2 \alpha$-helical segments are relatively rigid, whereas other regions are flexible.

The average solution structure of fowlicidin-2 indicated that it has 2 well-defined $\alpha$-helices from $\mathrm{Arg}^{6}$ to $\mathrm{Arg}^{12}$ and from $\mathrm{Ile}^{23}$ to $\mathrm{Gly}^{27}$, a bend from $\mathrm{Phe}^{17}$ to $\mathrm{Lys}^{20}$ and a flexible region at the $\mathrm{N}$-terminus from $\mathrm{Leu}^{1}$ to $\mathrm{Arg}^{4}$ (fig. 3a, b). In contrast to most $\alpha$-helical cathelicidins with a limited degree of kink (mostly induced by glycine) near the center $[21,22,32,33]$, the kink of fowlicidin- 2 in the central region is extensive, due to the presence of Pro $^{19}$. A closer examination revealed that the N-terminal $\alpha$-helix adopts a typical amphipathic structure, while the 

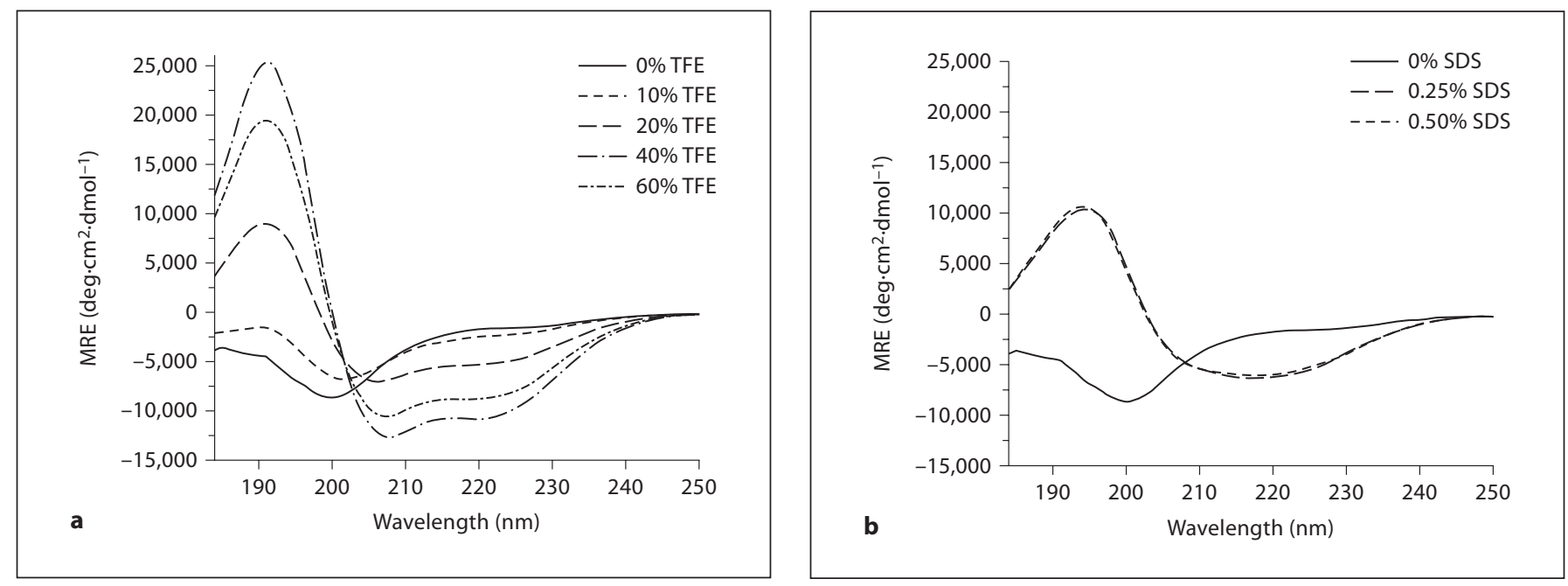

Fig. 1. CD spectrum of fowlicidin-2 and its analogs. a CD spectra in different concentrations of TFE. $\mathbf{b}$ CD spectra in different concentrations of SDS. c CD spectra of fowlicidin-2 analogs in $60 \%$ of TFE. The spectra were recorded at $10 \mu \mathrm{M}$ of peptides in $50 \mathrm{mM}$ potassium phosphate buffer, $\mathrm{pH}$ 7.4, with and without TFE or SDS.
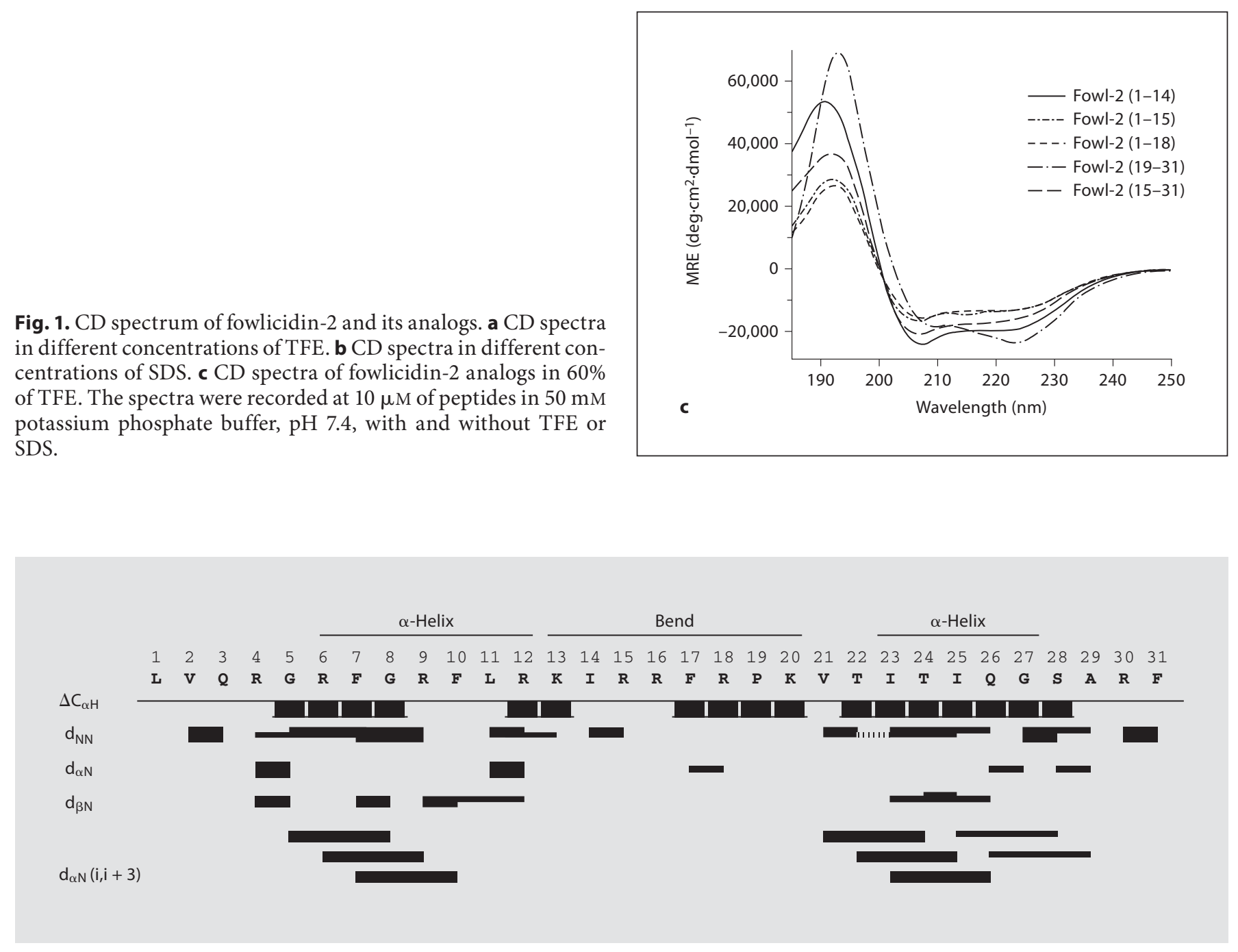

Fig. 2. The sequential and medium distance NOE connectivities and $\mathrm{C} \alpha$-proton chemical shift index $\left(\Delta \mathrm{C}_{\alpha \mathrm{H}}\right)$ for fowlicidin-2. Unambiguous connectivities are represented by solid lines, and overlapping connectivities by discontinuous lines. The thickness of the bar is proportional to the strength of the NOE connectivities. 
Table 2. Structural statistics of the 10 lowest energy structures of fowlicidin-2

\begin{tabular}{lc}
\hline NOE constraints, $\mathrm{n}$ & \\
Total & 174 \\
Intraresidue & 74 \\
Sequential & 53 \\
Medium range & 37 \\
Long range & 6 \\
Energies, kcal/mol & \\
Overall & $-203.70 \pm 27.32$ \\
Bonds & $72.52 \pm 1.09$ \\
Angles & $75.77 \pm 8.12$ \\
Improper & $0.28 \pm 0.11$ \\
Van der Waals & $-141.07 \pm 12.59$ \\
Electrostatic & $-211.21 \pm 13.66$ \\
Pairwise r.m.s.d. for residues $1-31, \AA$ & \\
Backbone & $3.86 \pm 0.98$ \\
Heavy atoms & $5.73 \pm 1.20$ \\
r.m.s.d. to mean structure (backbone/heavy atoms), \\
Residues 6-12 & $1.55 / 3.68$ \\
Residues $23-27$ & $0.28 / 1.34$ \\
Percentage of residues in regions of $\phi-\psi$ space \\
Core & $64.5 \%$ \\
Allowed & $29.0 \%$ \\
Generously allowed & $3.2 \%$ \\
Disallowed & $3.2 \%$ \\
\hline
\end{tabular}

r.m.s.d. = Root mean square deviation .

C-terminal $\alpha$-helix is highly hydrophobic (compare fig. $3 \mathrm{c}$ and d). It is noted that the central kink region of fowlicidin-2 carries a strong positive charge (fig. $3 c$, d), containing 5 cationic residues. The atomic coordinates and structure factors of fowlicidin-2 have been deposited under code 2GDL in the Protein Data Bank, Research Collaboratory for Structural Bioinformatics, Rutgers University, New Brunswick, N.J., USA (www.rcsb.org).

\section{Design and Conformation of Fowlicidin-2 Analogs}

To probe the impact of 2 short helical segments and the central kink region on the antibacterial, cytotoxic and LPS-binding activities of fowlicidin-2, several analogs with deletion of either $\mathrm{N}$ - or C-terminal residues were designed (table 1), synthesized chemically and purified to $>95 \%$ homogeneity by reverse-phase HPLC. The mass and purity of each peptide were further confirmed by mass spectrometry (table 1). The secondary structural contents of each peptide were determined by CD spectroscopy in the presence of $60 \%$ TFE, showing each peptide analog with a higher degree of $\alpha$-helicity than the parent peptide (fig. 1c). Three C-terminal deletion analogs, namely fowlicidin-2(1-14), fowlicidin-2(1-15) and fowlicidin-2(1-18), have a gradual increase in the $\alpha$-helical content, ranging from 44 and 53 to $62 \%$, respectively, suggesting that residues $15-18$ in the central kink region of the parent peptide likely adopt an $\alpha$-helical conformation without Pro ${ }^{19}$. The $\alpha$-helical content of $2 \mathrm{~N}$-terminal deletion analogs, fowlicidin-2(15-31) and fowlicidin-2(19-31), were estimated to be 42 and $79 \%$, respectively, which is consistent with the secondary structural contents predicted from the parent peptide. A similar trend also occurred with each analog in $0.5 \%$ SDS (data not shown).

\section{Antibacterial Activities of Fowlicidin-2 and Its Analogs}

A modified broth microdilution assay was used to test the antibacterial activity of fowlicidin-2 and its analogs using a bicarbonate-based buffer as described [28]. Three representative Gram-negative and 4 Gram-positive bacterial strains, including methicillin-resistant $S$. aureus, were included in the assay. As shown in table 3, fowlicidin-2 is potent against all strains with the MIC values in the range of $0.5-2 \mu \mathrm{M}$ with and without $100 \mathrm{mM} \mathrm{NaCl}$. In contrast, the analog containing only the $\mathrm{N}$-terminal $\alpha$ helix [fowlicidin-2(1-14)] exhibited $\geq 8$-fold reduction in antibacterial activity. The analog consisting solely of the C-terminal $\alpha$-helix [fowlicidin-2(19-31)] failed to kill bacteria even at $32 \mu \mathrm{M}$, the highest concentration tested. These results suggested neither $\alpha$-helical segments alone are sufficient to maintain the antibacterial activity of the parent peptide.

As compared with fowlicidin-2(1-14), fowlicidin-2(115) and fowlicidin-2(1-18) with inclusion of additional positively charged residues in the central kink region of the parent peptide showed a gradual increase in antibacterial potency (table 3). This is consistent with earlier observations that a simultaneous increase in cationicity and $\alpha$ helicity is often directly correlated with antibacterial efficacy [10, 11]. Fowlicidin-2(1-18) with a concurrent increase of +3 in the net charge and $18 \%$ in the $\alpha$-helical content exhibited 8- to 16 -fold enhancement in bactericidal efficiency, as compared with fowlicidin-2(1-14). In fact, the MIC values of fowlicidin-2(1-18) approached those of the parent peptide, with only $\leq 2$-fold difference against all bacteria tested (table 3 ). These results demonstrated the critical involvement of the 4 amino acids in the bending region from $\mathrm{Arg}^{15}$ to $\mathrm{Arg}^{18}$ in killing bacteria.

Relative to fowlicidin-2(19-31), fowlicidin-2(15-31) containing additional residues from $\mathrm{Arg}^{15}$ to $\mathrm{Arg}^{18}$ also demonstrated significant antibacterial activities, with only 2- to 4-fold reductions in MIC as compared with the 
Fig. 3. Views of the average solution structure of fowlicidin-2 in 50\% TFE. a Ribbon representation of the backbone trace of restrained energy-minimized average structure. $\mathbf{b} 90^{\circ}$ rotation of the structure in $\mathbf{a}$ around the $\mathrm{x}$-axis. $\mathrm{c}$ The accessible surface (same view as in a). $\mathbf{d} 180^{\circ}$ rotation of the surface plot in c around the $y$-axis. In $\mathbf{c}$ and d, basic residues are in shown in blue, hydrophobic residues are yellow and polar uncharged residues are white. $\mathbf{a}$ and $\mathbf{b}$ were generated with Sybyl 7.1, and $\mathbf{c}$ and $\mathbf{d}$ with GRASP.

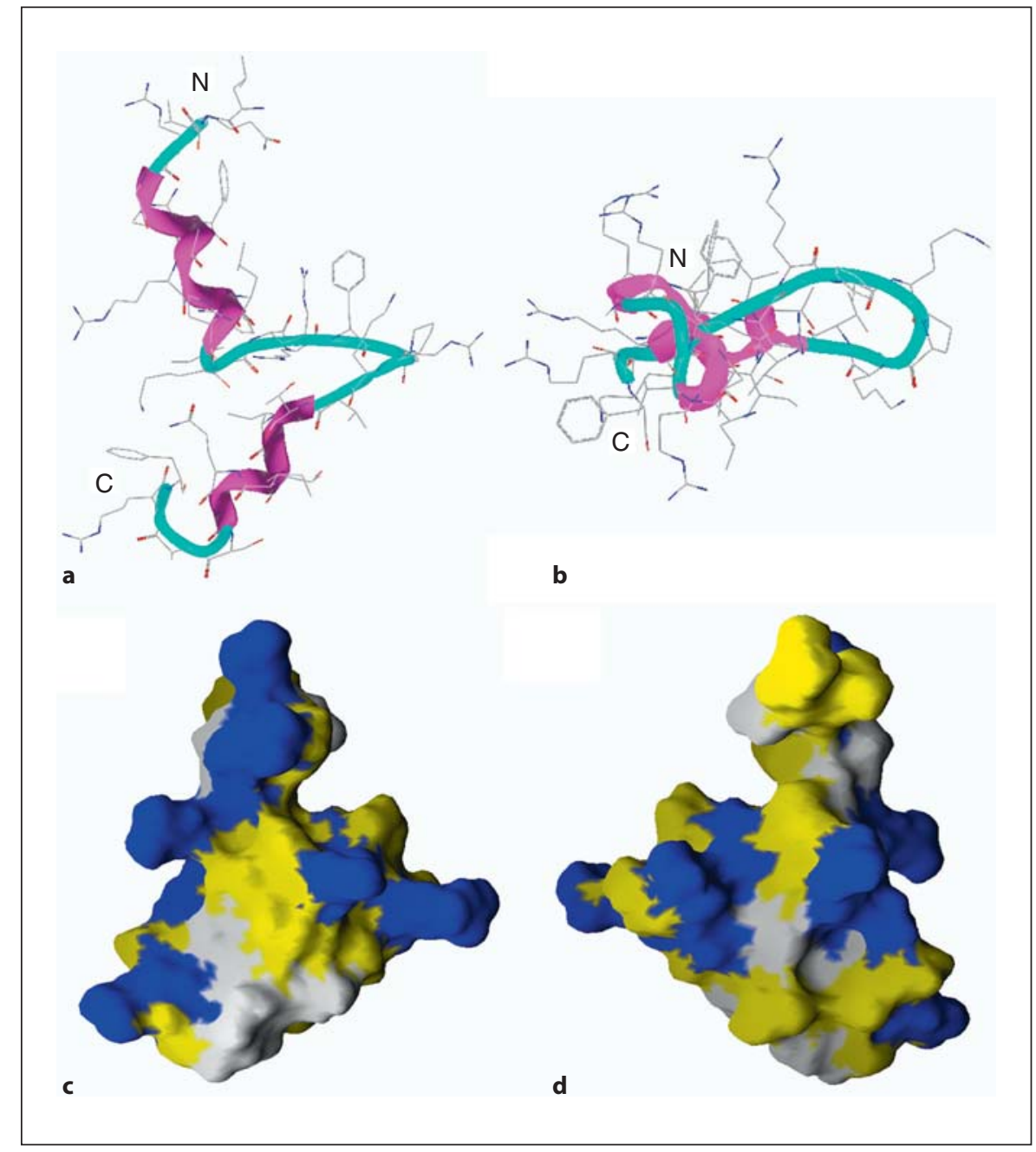

parent peptide. These results further confirmed that the 4-amino-acid segment from $\mathrm{Arg}^{15}$ to $\mathrm{Arg}^{18}$ in the central kink region is of vital importance in maintaining the bactericidal activity of fowlicidin-2.

Many antimicrobial peptides show a reduced antibacterial activity in the presence of serum or physiological concentrations of $\mathrm{NaCl}[6-8,34]$. However, none of the fowlicidin-2 analogs displayed $>2$-fold reduction in MIC in the presence of $100 \mathrm{mM} \mathrm{NaCl}$ (table 3). It is particularly true with fowlicidin-2(1-18) and fowlicidin-2(1531), whose antibacterial activities were largely unaffected by salt. The effect of serum on the antibacterial potency of peptides was also tested against S. aureus ATCC 29523 by a radial diffusion assay $[29,30]$ using $0.5 \mu \mathrm{g} /$ well of each peptide in the presence and absence of 20 or $50 \%$ human serum. As shown in figure 4 , serum did not affect the antibacterial activity of the parent peptide or fowlici- din-2(15-31), but inhibited the activities of 3 C-terminal deletion analogs, namely fowlicidin-2(1-14), fowlicidin2(1-15) and fowlicidin-2(1-18). Because of different sensitivity to serum, fowlicidin-2(1-18) may only be appropriate for topical applications, whereas fowlicidin-2(1531) appears to be suitable for both topical and systemic administrations.

\section{Permeabilization of Bacterial Cytoplasmic Membrane} by Fowlicidin-2 and Its Analogs

Electrostatic interaction with and subsequent disruption of bacterial membranes is a common mode of action for most antimicrobial peptides $[1,4,5]$. The ability of fowlicidin-2 and its analogs to permeabilize the inner membranes of bacteria was assessed by using $0.5 \mathrm{MIC}$ of each peptide and E. coli strain ML-35p, as previously described $[21,28]$. As shown in figure 5, full-length fowlici- 
Fig. 4. Effect of serum on the antibacterial activity of fowlicidin-2 and its analogs. The antibacterial activity was measured by the radial diffusion assay using $S$. aureus ATCC 25923 and $0.5 \mu \mathrm{g}$ of each peptide in the presence and absence of $20 \%$ or $50 \%$ of human serum. The bacterial clearance zones were visualized following overnight incubation at $37^{\circ} \mathrm{C}$. The results are representative of 2 independent experiments.

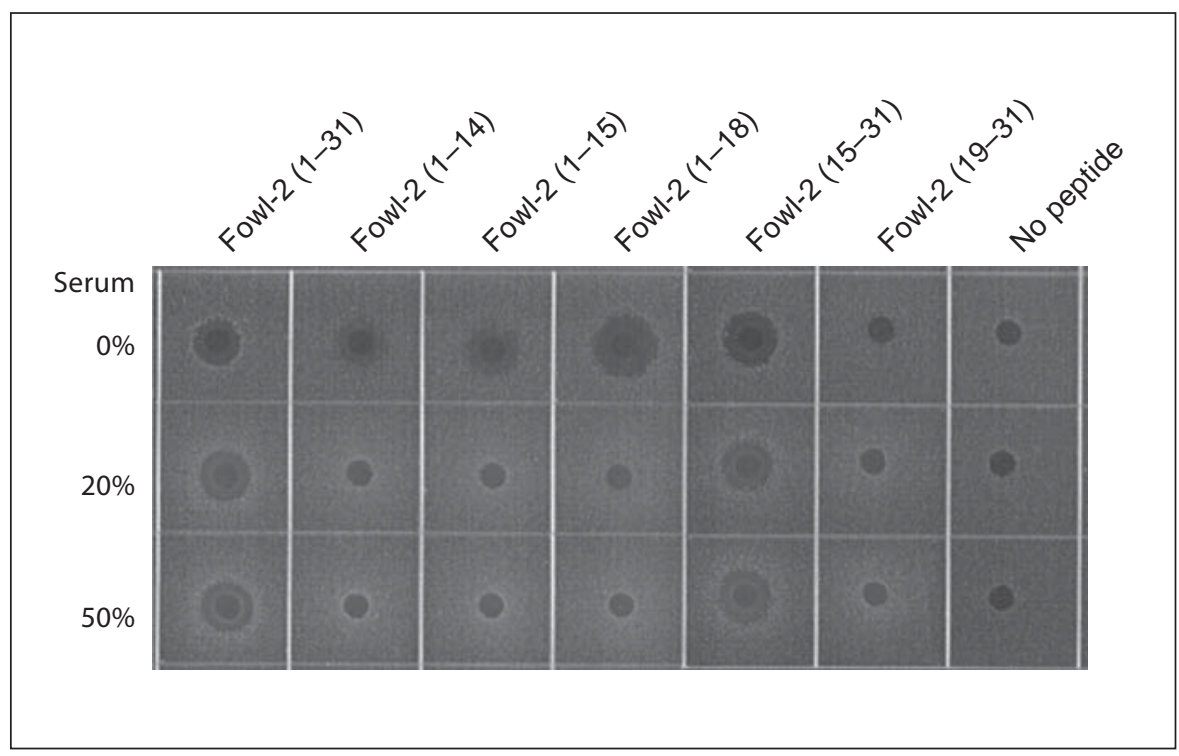

Table 3. Antibacterial activity of fowlicidin-2 and its analogs

\begin{tabular}{|c|c|c|c|c|c|c|c|c|c|c|c|c|c|}
\hline \multirow[t]{3}{*}{ Bacteria } & \multirow{3}{*}{$\begin{array}{l}\text { ATCC } \\
\text { No. }\end{array}$} & \multicolumn{12}{|c|}{ MIC, $\mu \mathrm{M}$} \\
\hline & & \multicolumn{2}{|c|}{ fowl-2(1-31) } & \multicolumn{2}{|c|}{ fowl-2(1-14) } & \multicolumn{2}{|c|}{ fowl-2(1-15) } & \multicolumn{2}{|c|}{ fowl-2(1-18) } & \multicolumn{2}{|c|}{ fowl-2(15-31) } & \multicolumn{2}{|c|}{ fowl-2(19-31) } \\
\hline & & 0 & 100 & 0 & 100 & 0 & 100 & 0 & 100 & 0 & 100 & 0 & 100 \\
\hline \multicolumn{14}{|l|}{ Gram-negative } \\
\hline E. coli & 25922 & 2 & 2 & $16 \sim 32$ & 32 & 16 & 16 & 4 & $4 \sim 8$ & $4 \sim 8$ & 8 & $>32$ & $>32$ \\
\hline S. enterica Serovar & & & & & & & & & & & & & \\
\hline enteritidis & 13076 & 1 & 1 & 16 & 16 & 4 & $4 \sim 8$ & 2 & 2 & 4 & 4 & $>32$ & $>32$ \\
\hline K. pneumoniae & 13883 & 2 & 2 & 16 & 32 & 8 & 16 & 2 & 2 & 4 & 4 & $>32$ & $>32$ \\
\hline \multicolumn{14}{|l|}{ Gram-positive } \\
\hline L. monocytogenes & 19115 & 2 & 2 & $16 \sim 32$ & 32 & $4 \sim 8$ & $8 \sim 16$ & 2 & 2 & $2 \sim 4$ & 4 & $>32$ & $>32$ \\
\hline S. aureus & 25923 & 0.5 & 2 & $8 \sim 16$ & $>32$ & 8 & 16 & 2 & 2 & $2 \sim 4$ & 4 & $>32$ & $>32$ \\
\hline S. aureus (MRSA) ${ }^{1}$ & BAA-39 & $1 \sim 2$ & $1 \sim 2$ & 32 & $>32$ & $4 \sim 8$ & 16 & 2 & $2 \sim 4$ & 4 & 4 & $>32$ & $>32$ \\
\hline S. aureus (MRSA) & 43300 & 1 & $1 \sim 2$ & 32 & $>32$ & $4 \sim 8$ & 16 & 2 & 2 & 2 & 4 & $>32$ & $>32$ \\
\hline
\end{tabular}

Mid-log phase bacteria $\left(5 \times 10^{5} \mathrm{CFU} / \mathrm{ml}\right)$ were incubated overnight with serial 2 -fold dilutions of each peptide in the assay medium containing 20\% TSB, $25 \mathrm{mM} \mathrm{NaHCO}_{3}$ and $1 \mathrm{mM}$ $\mathrm{NaH}_{2} \mathrm{PO}_{4}$ in the presence or absence of $100 \mathrm{mM} \mathrm{NaCl}$ (shown, respectively, as 0 or 100 in the heading line). The MIC value of in- dividual peptides against each bacterial strain was determined as the peptide concentration that gave no visible bacterial growth after overnight incubation. The experiments were repeated at least 3 times and the ranges of MICs are presented. MRSA $=\mathrm{Me}-$ thicillin-resistant $S$. aureus. din-2 permeabilized E. coli inner membrane quickly in a time-dependent fashion, with permeabilization occurring almost immediately upon contact of the peptide with the bacteria and the peak level being reached within 50-60 min, which was consistent with our earlier timekill assay that showed fowlicidin-2 achieved maximum bacterial killing within 30-60 min of incubation [20].
These results also suggested that physical membrane disruption is the major mechanism of bacterial killing by fowlicidin-2. In agreement with the broth microdilution assay (table 3) and the radial diffusion assay (fig. 4), salt did not affect the killing kinetics of fowlicidin-2 (fig. 5).

All 3 C-terminal deletion analogs at $0.5 \mathrm{MIC}$ showed a significant delay in bacterial membrane permeabiliza- 


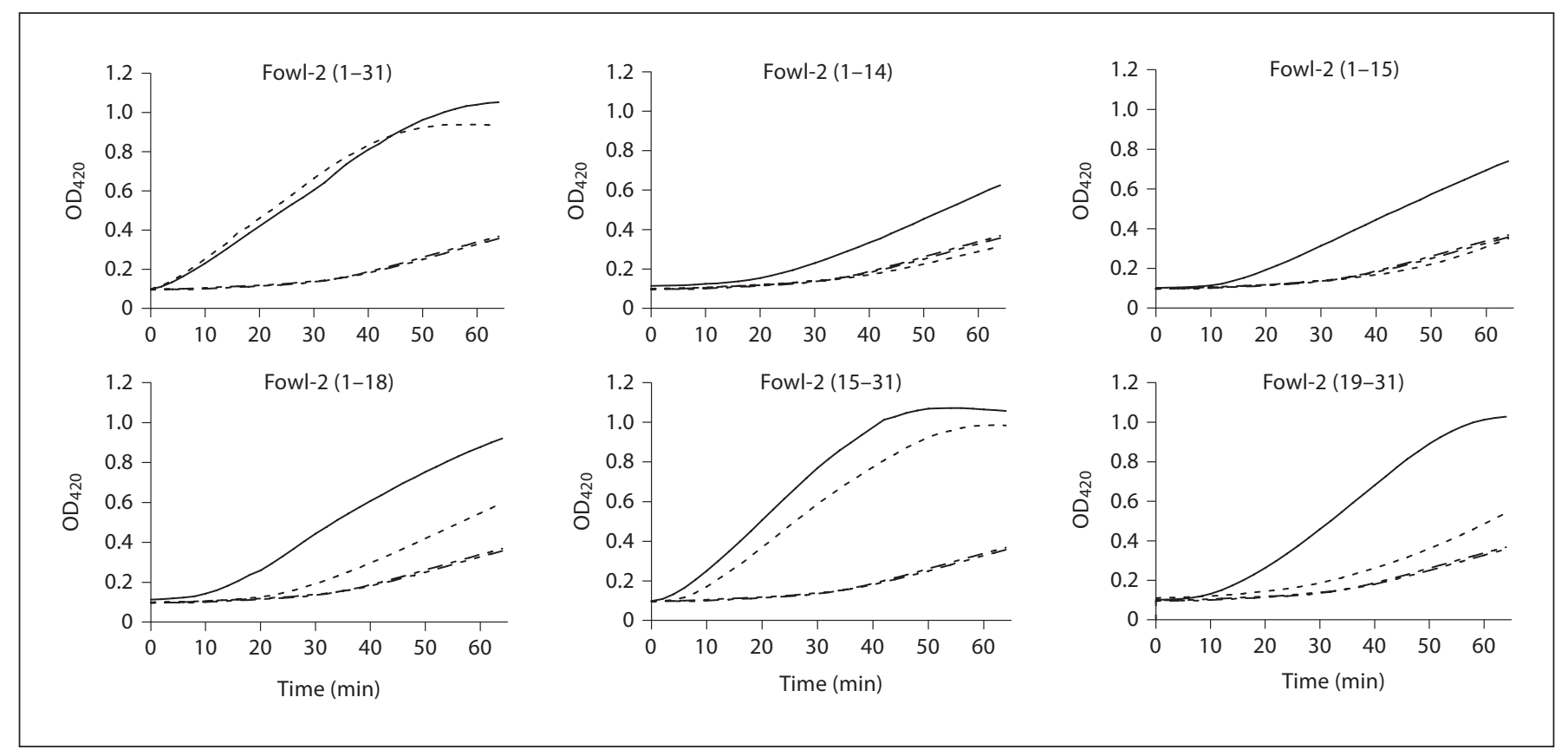

Fig. 5. Permeabilization of E. coli cytoplasmic membrane of fowlicidin-2 and its analogs. E. coli ML-35p was incubated with each peptide and $1.5 \mathrm{mM}$ of a chromogenic substrate (ONPG) in the presence and absence of $100 \mathrm{~mm} \mathrm{NaCl}$. All peptides were used at 0.5 MIC, except for fowlicidin-2(19-31), which was applied at $16 \mu \mathrm{M}$. The inner membrane permeability of each peptide was monitored every 2 min for $1 \mathrm{~h}$ at $37^{\circ} \mathrm{C}$ for the production of $o$-nitrophenol at $420 \mathrm{~nm}$. _ = Peptide; - - - - = peptide with $100 \mathrm{mM} \mathrm{NaCl}$; - - - - = no peptide; - - - - - = no peptide with $100 \mathrm{mM} \mathrm{NaCl}$. The results are representative of 2 independent experiments.

tion, which did not occur until approximately $20 \mathrm{~min}$ for fowlicidin-2(1-14), 10-15 min for fowlicidin-2(1-15) and around $5 \mathrm{~min}$ for fowlicidin-2(1-18) (fig. 5), indicating that the N-terminal $\alpha$-helical segment alone is not efficient in membrane interaction. Peak membrane perturbation was also delayed by $50-60 \mathrm{~min}$ for fowlicidin- 2 (1-14) and fowlicidin-2(1-15), and by 10-20 min for fowlicidin-2(1-18) in the absence of salt (data not shown). Presence of salt further delayed membrane permeabilization for all 3 analogs with fowlicidin-2(1-14) and fowlicidin-2(1-15) remaining largely inactive within $1 \mathrm{~h}$ (fig. 5). A comparison among $3 \mathrm{C}$-terminal deletion analogs suggested that cationicity and $\alpha$-helicity are positively correlated with the kinetics of membrane interaction and permeabilization with and without salt (fig. 5).

Two N-terminal deletion analogs, fowlicidin-2(15-31) and fowlicidin-2(19-31), also showed time-dependent membrane lysis of E. coli (fig. 5), indicating that, in contrast to the $\mathrm{N}$-terminal $\alpha$-helix, the $\mathrm{C}$-terminal $\alpha$-helix alone appears to be capable of interacting and permeabilizing bacterial membranes. Impressively, fowlicidin2(15-31) with inclusion of the 4 amino-acid segment from
$\mathrm{Arg}^{15}$ to $\mathrm{Arg}^{18}$ showed similar kinetics of membrane permeabilization to the full-length peptide and, furthermore, such an activity was not affected by salt (fig. 5). Collectively, these observations confirmed that the central cationic kink region is critical in mediating salt-resistant interactions between peptides and bacterial membranes.

\section{Cytotoxicity of Fowlicidin-2 and Its Analogs}

To identify the region(s) that are involved in cytotoxicity, fowlicidin-2 and its analogs were tested for their toxicities to human erythrocytes and colonic epithelial Caco-2 cells, as previously described [20, 21]. The fulllength fowlicidin-2 peptide displayed a noticeable, dosedependent hemolytic activity. At $200 \mu \mathrm{M}$, fowlicidin-2 lysed 80 and $100 \%$ of erythrocytes in the presence (fig. $6 \mathrm{a}$ ) and absence (fig. $6 \mathrm{~b}$ ) of $10 \%$ FBS, respectively. Remarkably, all 3 C-terminal deletion analogs and fowlicidin$2(19-31)$ showed essentially no hemolysis even at $200 \mu \mathrm{M}$, regardless of serum (fig. 6a, b). Fowlicidin-2(15-31), when applied at $200 \mu \mathrm{M}$, also lost hemolytic activity in the presence of serum (fig. 6a), and only exhibited $30 \%$ of lysis in the absence of serum (fig. 6b). 


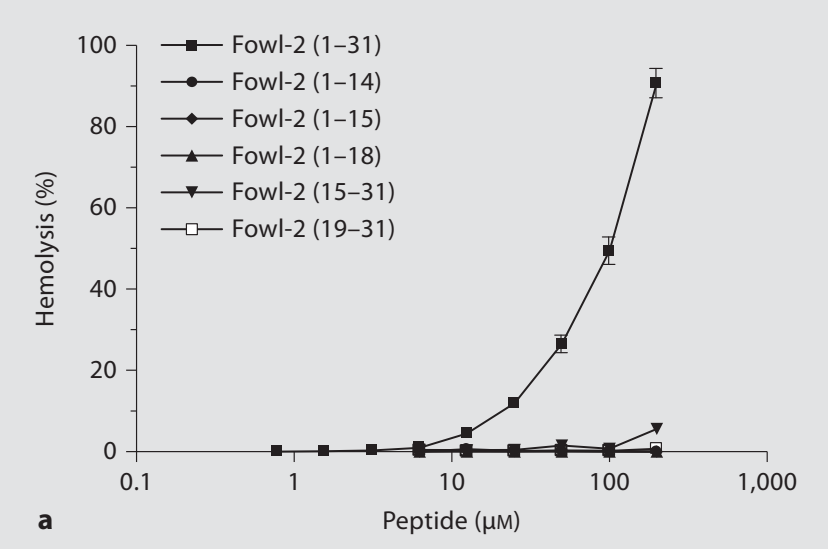

Fig. 6. Cytotoxicity of fowlicidin-2 and its analogs. Hemolytic activity was evaluated by incubating individual peptides in serial 2 -fold dilutions with freshly isolated human erythrocytes in the presence (a) or absence (b) of $10 \% \mathrm{FBS}$ at $37^{\circ} \mathrm{C}$ for $2 \mathrm{~h}$, followed by measuring the released hemoglobin at $405 \mathrm{~nm}$. c Toxicity to human Caco-2 cells. Peptides at $100 \mu \mathrm{M}$ were incubated with Caco- 2 cells at $37^{\circ} \mathrm{C}$ for $24 \mathrm{~h}$, and cell viabilities were measured by an alamarBlue-based, colorimetric method. The data shown are means \pm SEM of 2 or 3 independent experiments.

As for Caco-2 cells, the full-length peptide showed $100 \%$ killing in the presence of $10 \%$ FBS and 30\% killing without FBS, whereas all analogs lost their toxicity significantly. Fowlicidin-2(1-14), fowlicidin-2(1-15) and fowlicidin-2(19-31) caused only a negligible degree of cell death when $100 \mu \mathrm{M}$ was used with and without serum (fig. 6c). Fowlicidin-2(1-18) and fowlicidin-2(15-31) caused 15 and $55 \%$ cell death at $100 \mu \mathrm{M}$ without serum, respectively, whereas serum reduced the cytotoxicity of both peptides to a minimum (8\%).

\section{LPS-Neutralizing Activities of Fowlicidin-2 and Its Analogs}

We have shown that fowlicidin-2 is capable of binding to LPS and further blocking LPS-induced inflammatory gene expression in RAW264.7 mouse macrophage cells [20]. To further map the region(s) responsible for the LPSneutralizing activity, RAW264.7 cells were stimulated in
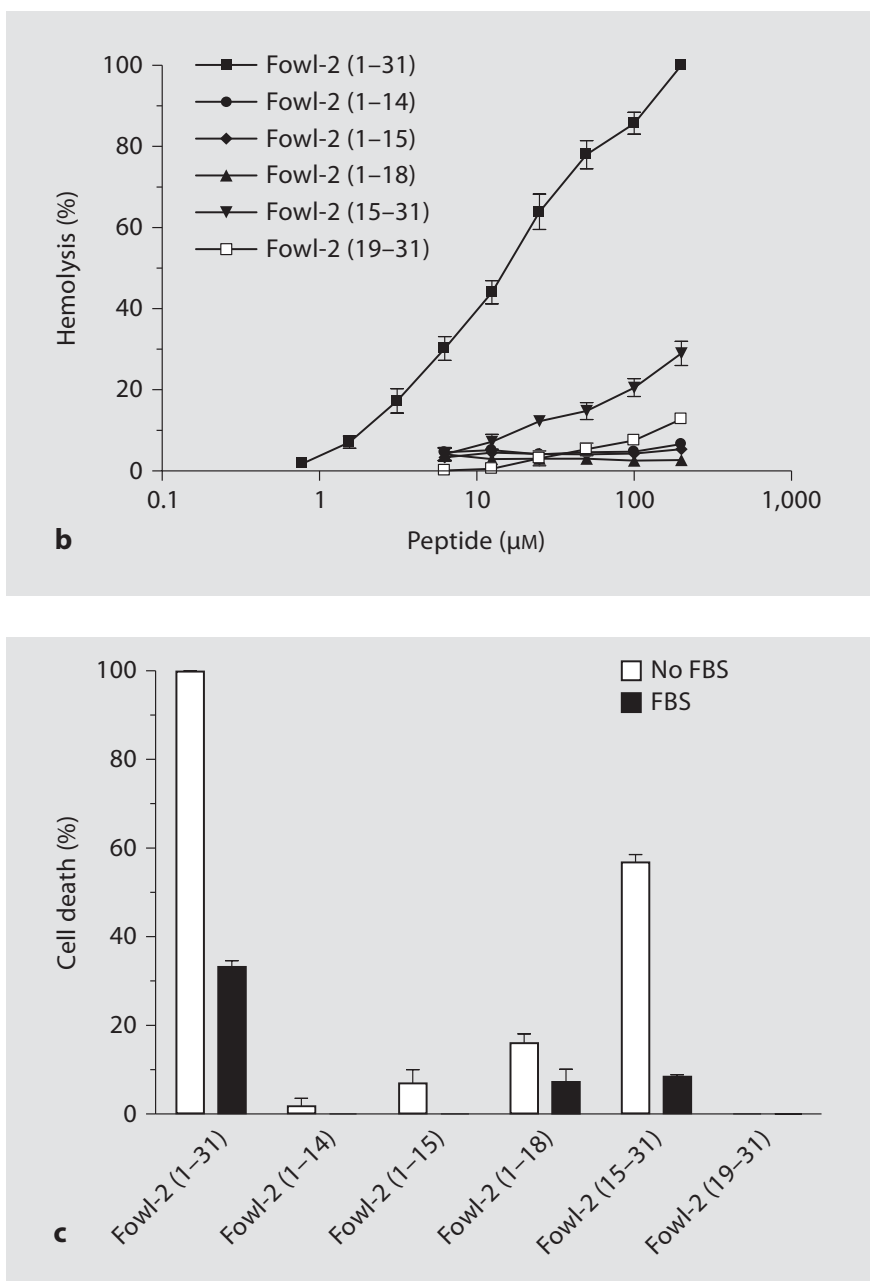

serum-free medium for $24 \mathrm{~h}$ with $0.1 \mu \mathrm{g} / \mathrm{ml}$ of LPS in the presence or absence of $20 \mu \mathrm{M}$ of fowlicidin- 2 and its analogs. The concentrations of 2 common proinflammatory mediators, namely TNF- $\alpha$ and NO, were measured in cell culture supernatants. Consistent with our earlier observation [20], full-length fowlicidin-2 displayed potent LPS-neutralizing activity, with $>95 \%$ inhibition in TNF$\alpha$ production (fig. 7a). Two analogs containing the N-terminal $\alpha$-helix [fowlicidin-2(1-14) and fowlicidin-2(1-15)] also suppressed LPS-induced TNF- $\alpha$ production by $40-$ $55 \%$, suggesting that the $\mathrm{N}$-terminal $\alpha$-helix constitutes an LPS binding and neutralization site. A similar trend in inhibiting NO production was also observed with fowlicidin-2(1-14) and fowlicidin-2(1-15) (fig. 7b). As expected, inclusion of cationic residues with the $\mathrm{N}$-terminal $\alpha$-helix [fowlicidin-2(1-18)] potentiated the binding and neutralization of anionic LPS, particularly in suppression of NO production. 

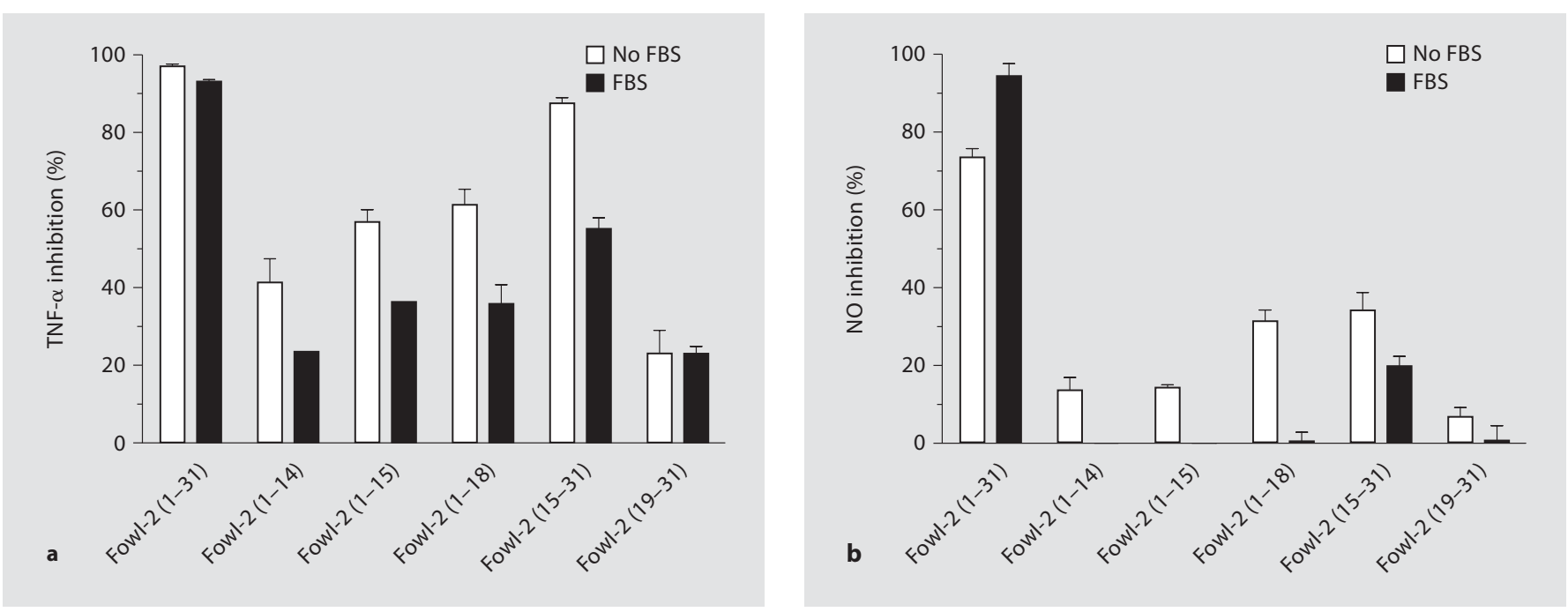

Fig. 7. Neutralization of LPS by fowlicidin- 2 and its analogs. RAW 264.7 cells were stimulated for $24 \mathrm{~h}$ with 0.1 $\mu \mathrm{g} / \mathrm{ml} \mathrm{LPS}$ and $20 \mu \mathrm{M}$ peptides in cell culture medium with and without $10 \%$ FBS. The levels of TNF- $\alpha$ (a) and NO (b) in cell culture supernatants were measured by ELISA and Griess reagent, respectively. Data shown are means \pm SEM of 2 or 3 independent experiments.

However, the analog containing entirely the C-terminal $\alpha$-helix [fowlicidin-2(19-31)] showed minimum inhibition of LPS-induced production of TNF- $\alpha$ and NO (fig. 7), indicating that, in contrast to the $\mathrm{N}$-terminal $\alpha$ helix, the C-terminal $\alpha$-helix alone is not sufficient for LPS binding and neutralization. The failure of fowlicidin-2(19-31) to interact with LPS is likely due to the fact that this segment is relatively hydrophobic, with a net charge of +2 , whereas the $\mathrm{N}$-terminal 14 residues are amphipathic, with a net charge of +5 . However, inclusion of the cationic, 4 amino-acid segment with the C-terminal $\alpha$-helix [fowlicidin-2(15-31)] gave rise to the most suppressive activity in TNF- $\alpha$ and NO production, implying the central kink region is critical in mediating the binding of cationic peptides to anionic LPS. Thus, the segment containing residues 15-31 constitutes the second LPS binding and neutralization site, consistent with our earlier prediction that the full-length fowlicidin-2 is composed of at least 2 LPS-binding sites [20].

The inclusion of $10 \%$ FBS in the cell culture medium suppressed LPS-neutralizing activity for all peptide analogs with nearly complete loss of the NO inhibitory activity, except for fowlicidin-2(15-31), which inhibited LPSinduced NO production by approximately $20 \%$ in the presence of serum (fig. 7b). The relative resistance of fowlicidin-2(15-31) to serum is also in agreement with its maintenance of the antibacterial activity in human or chicken serum (fig. 4).
It is notable that at $20 \mu \mathrm{M}$ neither fowlicidin- 2 nor its analogs exerted noticeable toxicity or morphological changes on RAW264.7 cells with or without inclusion of $10 \%$ FBS in culture medium. Furthermore, no peptide analogs alone caused alterations in TNF- $\alpha$ and NO levels when incubated with RAW264.7 cells (data not shown), suggesting that the inhibitory effect was specifically due to LPS-peptide interactions.

\section{Discussion}

An alignment of over $150 \alpha$-helical antimicrobial host defense peptides revealed that many consist of a short central hinge sequence, due to the presence of a glycine [10]. The presence or introduction of such a hinge in the helix has been shown to increase the flexibility of the $\alpha$-helix and in many cases to be desirable, attenuating the toxicity of peptides to host cells while maintaining comparable antimicrobial potency with the peptides with no hinge $[10,11,35]$. A similar glycine-induced hinge is also present near the center of fowlicidins 1 and 3 [21,22]. In contrast, fowlicidin- 2 consists primarily of 2 short $\alpha$-helices (residues 6-12 and 23-27), connected by an extensive kink region (residues 13-20) induced by Pro $^{19}$ (fig. 3). The N-terminal $\alpha$-helix adopts a typical amphipathic structure, whereas the C-terminal helix is more hydrophobic. The central kink region of fowlicidin-2 has a strong positive 
charge and contains 5 cationic residues. Fowlicidins 1 and 3 , on the other hand, are composed of 2 hydrophobic $\alpha$ helices separated by a slight glycine-induced kink $[21,22]$. Most of the cationic residues of fowlicidins 1 and 3 are instead concentrated at either end $[21,22]$. Such structural differences between fowlicidin- 2 and other $\alpha$-helical antimicrobial peptides suggest that fowlicidin- 2 might be functionally different from fowlicidins 1 and 3 and other peptides.

By studying several fowlicidin-2 analogs with deletions of certain structural components, we have been able to determine the significance of the $2 \alpha$-helices and the central kink region in the antibacterial, cytotoxic and LPS-neutralizing activities. Because fowlicidin-2(1-14) and fowlicidin-2(19-31) displayed no toxicity at all against either human erythrocytes or epithelial cells (fig. 6), it is obvious that neither the $\mathrm{N}$ - or C-terminal $\alpha$ helix alone is sufficient in the interaction with and permeabilization of mammalian cell membranes. Therefore, apparent cytotoxicity of the full-length fowlicidin-2 must be caused by the amino acid sequence in the central kink region. However, the 2 analogs containing $\mathrm{Arg}^{15}$ to $\mathrm{Arg}^{18}$ [fowlicidin-2(1-18) and fowlicidin-2(15-31)] exhibited substantially reduced cytotoxicities, although they were still higher than those of the peptide analogs containing the $\alpha$-helix alone. The obvious reduction in toxicity associated with fowlicidin-2(1-18) and fowlicidin-2(15-31) is likely due to the conformational differences of the 4 amino-acid segment $\left(\mathrm{Arg}^{15}\right.$ to $\left.\mathrm{Arg}^{18}\right)$ in these 2 analogs, as opposed to in the full-length peptide.

We have also revealed that the C-terminal $\alpha$-helix alone [fowlicidin-2(19-31)] has no antibacterial or LPSneutralizing activities (table 3 , fig. 7). Moreover, the $\mathrm{N}$ terminal $\alpha$-helix [fowlicidin-2(1-14)] is weakly active against bacteria that have relatively low capacities to neutralize LPS (table 3, fig. 7). These results indicated that neither $\alpha$-helical segment per se is sufficient to bind LPS and kill bacteria. However, it is interesting to note that both peptides are capable of permeabilizing the cytoplasmic membranes of E. coli ML-35p (fig. 5).

The addition of 4 amino acids in the central bending region $\left(\mathrm{Arg}^{15}\right.$ to $\left.\mathrm{Arg}^{18}\right)$ to the $\mathrm{N}$ - or $\mathrm{C}$-terminal $\alpha$-helical segment is associated with a significant enhancement in both antibacterial and LPS-neutralizing activities, suggesting that this central segment is critically important in membrane interactions. Given that this segment has a strong positive charge due to the presence of 3 arginines, it is not surprising that this cationic region is capable of promoting the interactions of fowlicidin-2 with anionic LPS and bacterial membranes.

Structure-Activity Relationships of Fowlicidin-2
Cationicity, $\alpha$-helicity and amphipathicity are among the most important physicochemical parameters that dictate the functional properties of $\alpha$-helical antimicrobial peptides [9-11]. To a certain degree, these 3 parameters are often positively correlated with the antibacterial activity. Consistent with these observations, a gradual increase in cationicity, $\alpha$-helicity and amphipathicity among all peptide analogs [fowlicidin-2(1-14), fowlicidin-2(1-15) and fowlicidin-2(1-18)] leads to a gradual enhancement in permeabilization of $E$. coli inner membranes (fig. 5), LPS neutralization (fig. 7) and antibacterial potency (table 3 ).

In summary, a comparison of the functional properties of all peptide analogs with those of the full-length fowlicidin-2 has enabled us to identify short analogs that have better therapeutic potentials. Although fowlicidin2(1-14), fowlicidin-2(1-15) and fowlicidin-2(19-31) lack cytotoxicity, their antibacterial and LPS-neutralizing activities are disappointing and are indicative of little clinical utility. On the other hand, fowlicidin-2(1-18) and fowlicidin-2(15-31) have an MIC of 2-4 $\mu \mathrm{M}$ against most bacteria tested (table 3 ), with a minimum toxicity to human erythrocytes or intestinal Caco-2 cells even at 100 $\mu \mathrm{M}$ in the presence of serum (fig. 6). Both fowlicidin-2(118) and fowlicidin-2(15-31) are capable of blocking LPSinduced proinflammatory responses in RAW264.7 cells at levels that approach that of the parent peptide (fig. 7). Moreover, these 2 short peptide analogs kill bacteria irrespective of salt, and the antibacterial activity of fowlicidin-2(15-31) is not affected by serum (table 3, fig. 4). Therefore, both peptides represent better candidates with a significant improvement in the therapeutic window and safety, as compared with the parent peptide. The in vivo toxicity and antibacterial and anti-LPS efficacy of fowlicidin-2(1-18) and fowlicidin-2(15-31) are currently under evaluation.

\section{Acknowledgements}

We thank Robert Gallo of University of California, San Diego, for kindly providing E. coli strain ML-35p for use in the inner membrane permeabilization assays. We also thank Steve Hartson of Oklahoma State University for helping with mass spectrometry. We are grateful to Ulrich Melcher for his critical reading of the manuscript. This work was supported by grants from the NIH (S10-RR022392), NSF (MCB0236039 and EPS0236913), USDA CSREES (2008-35204-04544), Kansas State University COBRE and Targeted Excellence Programs, Oklahoma Center for the Advancement of Science and Technology (HR03-146, HR07-113 and AR07.2-087) and Oklahoma Agricultural Experiment Station (H2507).

J Innate Immun 2009;1:268-280 279 


\section{References}

1 Zasloff M: Antimicrobial peptides of multicellular organisms. Nature 2002;415:389395.

$>2$ Hancock RE, Diamond G: The role of cationic antimicrobial peptides in innate host defences. Trends Microbiol 2000;8:402-410.

$\checkmark 3$ Selsted ME, Ouellette AJ: Mammalian defensins in the antimicrobial immune response. Nat Immunol 2005;6:551-557.

4 McPhee JB, Hancock RE: Function and therapeutic potential of host defence peptides. J Pept Sci 2005; 11:677-687.

5 Oren Z, Shai Y: Mode of action of linear amphipathic alpha-helical antimicrobial peptides. Biopolymers 1998;47:451-463.

$\checkmark 6$ Lee IH, Cho Y, Lehrer RI: Effects of $\mathrm{pH}$ and salinity on the antimicrobial properties of clavanins. Infect Immun 1997;65:28982903.

$\checkmark 7$ Ciornei CD, Sigurdardottir T, Schmidtchen A, Bodelsson M: Antimicrobial and chemoattractant activity, lipopolysaccharide neutralization, cytotoxicity, and inhibition by serum of analogs of human cathelicidin LL-37. Antimicrob Agents Chemother 2005 49:2845-2850.

$\checkmark 8$ Bartlett KH, McCray PB Jr, Thorne PS: Reduction in the bactericidal activity of selected cathelicidin peptides by bovine calf serum or exogenous endotoxin. Int J Antimicrob Agents 2004;23:606-612.

$\checkmark 9$ Chen Y, Mant CT, Farmer SW, Hancock RE, Vasil ML, Hodges RS: Rational design of alpha-helical antimicrobial peptides with enhanced activities and specificity/therapeutic index. J Biol Chem 2005;280:12316-12329.

10 Tossi A, Sandri L, Giangaspero A: Amphipathic, alpha-helical antimicrobial peptides. Biopolymers 2000;55:4-30.

11 Dathe M, Wieprecht T: Structural features of helical antimicrobial peptides: their potential to modulate activity on model membranes and biological cells. Biochim Biophys Acta 1999;1462:71-87.

12 Epand RM, Vogel HJ: Diversity of antimicrobial peptides and their mechanisms of action. Biochim Biophys Acta 1999;1462:1128.

-13 Zanetti M, Gennaro R, Skerlavaj B, Tomasinsig L, Circo R: Cathelicidin peptides as candidates for a novel class of antimicrobials. Curr Pharm Des 2002;8:779-793.

14 Bals R, Wilson JM: Cathelicidins: a family of multifunctional antimicrobial peptides. Cell Mol Life Sci 2003;60:711-720.
15 Zaiou M, Gallo RL: Cathelicidins, essential gene-encoded mammalian antibiotics. J Mol Med 2002;80:549-561.

16 Lehrer RI, Ganz T: Cathelicidins: a family of endogenous antimicrobial peptides. Curr Opin Hematol 2002;9:18-22.

17 Cirioni O, Giacometti A, Ghiselli R, Bergnach C, Orlando F, Silvestri C, Mocchegiani F, Licci A, Skerlavaj B, Rocchi M, Saba V, Zanetti M, Scalise G: LL-37 protects rats against lethal sepsis caused by Gram-negative bacteria. Antimicrob Agents Chemother 2006;50:1672-1679.

18 Giacometti A, Cirioni O, Ghiselli R, Bergnach C, Orlando F, D’Amato G, Mocchegiani F, Silvestri C, Del Prete MS, Skerlavaj B, Saba V, Zanetti M, Scalise G: The antimicrobial peptide BMAP-28 reduces lethality in mouse models of staphylococcal sepsis. Crit Care Med 2004;32:2485-2490.

19 Giacometti A, Cirioni O, Ghiselli R, Mocchegiani F, D’Amato G, Circo R, Orlando F, Skerlavaj B, Silvestri C, Saba V, Zanetti M, Scalise G: Cathelicidin peptide sheep myeloid antimicrobial peptide- 29 prevents endotoxin-induced mortality in rat models of septic shock. Am J Respir Crit Care Med 2004;169:187-194.

20 Xiao Y, Cai Y, Bommineni YR, Fernando SC, Prakash O, Gilliland SE, Zhang G: Identification and functional characterization of three chicken cathelicidins with potent antimicrobial activity. J Biol Chem 2006;281: 2858-2867.

21 Bommineni YR, Dai H, Gong YX, Soulages JL, Fernando SC, Desilva U, Prakash O, Zhang G: Fowlicidin-3 is an alpha-helical cationic host defense peptide with potent antibacterial and lipopolysaccharide-neutralizing activities. FEBS J 2007;274:418-428.

22 Xiao Y, Dai H, Bommineni YR, Soulages JL, Gong YX, Prakash O, Zhang G: Structureactivity relationships of fowlicidin-1, a cathelicidin antimicrobial peptide in chicken. FEBS J 2006;273:2581-2593.

23 Sreerama N, Venyaminov SY, Woody RW: Estimation of protein secondary structure from circular dichroism spectra: inclusion of denatured proteins with native proteins in the analysis. Anal Biochem 2000;287:243251.

24 Wüthrich K: NMR of Proteins and Nucleic Acids. New York, Wiley, 1986.

25 Wüthrich K, Billeter M, Braun W: Pseudostructures for the 20 common amino acids for use in studies of protein conformations by measurements of intramolecular protonproton distance constraints with nuclear magnetic resonance. J Mol Biol 1983;169: 949-961.
-26 Brunger AT, Adams PD, Clore GM, DeLano WL, Gros P, Grosse-Kunstleve RW, Jiang JS, Kuszewski J, Nilges M, Pannu NS, Read RJ, Rice LM, Simonson T, Warren GL: Crystallography and NMR system: a new software suite for macromolecular structure determination. Acta Crystallogr D Biol Crystallogr 1998;54:905-921.

27 Nicholls A, Sharp KA, Honig B: Protein folding and association: insights from the interfacial and thermodynamic properties of hydrocarbons. Proteins 1991;11:281-296.

28 Dorschner RA, Lopez-Garcia B, Peschel A, Kraus D, Morikawa K, Nizet V, Gallo RL: The mammalian ionic environment dictates microbial susceptibility to antimicrobial defense peptides. FASEB J 2006;20:35-42.

$\checkmark 29$ Steinberg DA, Lehrer RI: Designer assays for antimicrobial peptides: disputing the 'onesize-fits-all' theory. Methods Mol Biol 1997; 78:169-186.

30 Turner J, Cho Y, Dinh NN, Waring AJ, Lehrer RI: Activities of LL-37, a cathelin-associated antimicrobial peptide of human neutrophils. Antimicrob Agents Chemother 1998; 42:2206-2214.

-31 Laskowski RA, Rullmannn JA, MacArthur MW, Kaptein R, Thornton JM: AQUA and PROCHECK-NMR: programs for checking the quality of protein structures solved by NMR. J Biomol NMR 1996;8:477-486.

32 Yu K, Park K, Kang SW, Shin SY, Hahm KS, Kim Y: Solution structure of a cathelicidinderived antimicrobial peptide, CRAMP as determined by NMR spectroscopy. J Pept Res 2002;60:1-9.

33 Tack BF, Sawai MV, Kearney WR, Robertson AD, Sherman MA, Wang W, Hong T, Boo LM, Wu H, Waring AJ, Lehrer RI: SMAP-29 has two LPS-binding sites and a central hinge. Eur J Biochem 2002;269:1181-1189.

-34 Travis SM, Anderson NN, Forsyth WR, Espiritu C, Conway BD, Greenberg EP, McCray PB Jr., Lehrer RI, Welsh MJ, Tack BF: Bactericidal activity of mammalian cathelicidinderived peptides. Infect Immun 2000;68: 2748-2755.

-35 Sawai MV, Waring AJ, Kearney WR, McCray PB Jr, Forsyth WR, Lehrer RI, Tack BF: Impact of single-residue mutations on the structure and function of ovispirin/novispirin antimicrobial peptides. Protein Eng 2002;15:225-232. 